\title{
Variations in lateral abdominal muscle thickness during abdominal drawing-in maneuver in three positions in a young healthy population
}

\author{
Young Jun Ko ${ }^{a}$, Hyun Geun Ha ${ }^{a}$, Juri Jeong ${ }^{b}$, Wan Hee Lee ${ }^{c}$ \\ ${ }^{a}$ Department of Physical Medicine and Rehabilitation, Samsung Medical Center, Seoul, Republic of Korea \\ ${ }^{b}$ Korea National Rehabilitation Research Institute, Department of Clinical Rehabilitation, Seoul, Republic of Korea \\ 'Department of Physical Therapy, The Graduate School, Sahmyook University, Seoul, Republic of Korea
}

Objective: To investigate the appropriate position for abdominal drawing-in maneuver (ADIM) exercise by rehabilitative ultrasound image.

Design: Cross-sectional study.

Methods: Twenty-eight young adults with no history of low back pain participated in the study. Three positions compared were crook lying position with hip $60^{\circ}$ flexion, standing position with the feet hip width apart and knees straight, and saddle standing positionunsupported with the knees $20^{\circ}$ flexed. Once in the appropriate position, the subjects were verbally cued to draw in their abdominal wall, with the intention of pulling their navel inward toward their lower back. The thickness of each transversus abdominis (TrA), internal oblique (IO), and external oblique (EO) muscles were measured via ultrasound and recorded at the end of inspiration.

Results: When compared to the TrA thickness of rest, the TrA thickness was significantly increased in all three positions (crook lying, standing, and saddle standing) during the ADIM $(p<0.05)$. IO thickness was significantly greater in standing and saddle standing than in crook lying $(p<0.05)$. EO thickness was constant in all the three positions.

Conclusions: The present study suggests that standing and saddle standing positions could be recommended for the ADIM to maximize recruitment of the TrA and IO activation. Specifically, the saddle standing position with knees flexed to $20^{\circ}$ was observed to increase the TrA activation more than the standing position. These findings should be considered when core stability exercises such as the ADIM are conducted.

Key Words: Abdominal muscles, Position, Ultrasound

\section{Introduction}

Spinal stabilization exercises have been utilized as conservative treatment intervention for low back pain (LBP) and have been shown to decrease LBP symptoms [1,2]. These exercises attempt to restore function of local spine stabilization muscles including the transversus abdominis (TrA), multifidus, pelvic floor, and diaphragm [3,4]. The TrA is one of the dynamic stabilizer muscles pre-activated during functional movement. Much research has been published with regard to motor control and the sequencing of muscle contractions during the stabilization of the spine $[5,6]$. Previous studies suggest the $\operatorname{TrA}$ is consistently the first abdominal muscle to contract in an anticipatory feed-forward manner [7-9].

Since the TrA muscles are deep to other abdominal muscles, they are difficult to evaluate and palpate. Rehabilitative ultrasonographic imaging (RUSI) is a relatively simple and

Received: 30 July, 2014 Revised: 12 September, 2014 Accepted: 13 October, 2014

Corresponding author: Wan Hee Lee

Department of Physical Therapy, College of Health and Welfare, Sahmyook University, 815 Hwarang-ro, Nowon-gu, Seoul 139-742, Republic of Korea Tel: 82-2-3399-1633 Fax: 82-2-3399-1639 E-mail: whlee@syu.ac.kr

(c) This is an Open-Access article distributed under the terms of the Creative Commons Attribution Non-Commercial License (http://creativecommons.org/licens es/by-nc/3.0) which permits unrestricted non-commercial use, distribution, and reproduction in any medium, provided the original work is properly cited.

Copyright @ 2014 Korean Academy of Physical Therapy Rehabilitation Science 
accurate method for measuring the deep spinal musculature $[10,11]$. RUSI is a non-invasive, accessible, safe, and low-cost tool for muscle size measurement [12], with results comparable to those obtained with magnetic resonance imaging [13-16].

The abdominal drawing-in maneuver (ADIM) is commonly used clinically as a spinal stabilization exercise that isolates the $\operatorname{Tr} \mathrm{A}[3,4,17,18]$. The ADIM is designed to activate the TrA while minimally contracting the internal oblique (IO) and external oblique (EO) muscles [19]. Previous studies involving ADIM have been performed with subjects in various positions such as supine, crook lying, sitting, four points kneeling, and wall support standing [20-22]. O'Sullivan [23] recommends weight-bearing positions such as standing as a first ADIM exercise. Mew [22] and Akuthota and Nadler [24] also stated that standing positions were most effective for performing TrA contraction. In addition, Hwang et al. [21] studied variations in TrA contraction ratios with variation of knee flexion during ADIM in wall support, reporting that performing ADIM in the wall supported standing with knee flexion of $20^{\circ}$ appears to be the most appropriate position for the preferential contraction ratio of the TrA.

The ADIM may be conducted in various positions, and physical therapists need to ensure the best position for the ADIM to achieve optimal outcome. However, there has been little research on which position is most effective for the ADIM exercise.
This study is aimed to investigate the appropriate position for the ADIM exercise by using a RUSI.

\section{Methods}

\section{Subjects}

Twenty-eight young adults (14 men, 14 women, aged 19-29 years) with no history of LBP were recruited from the student population of the Sahmyook University in Seoul. The exclusion criteria were as follows: history of pelvic or abdominal surgery, current LBP, or pregnancy. All subjects completed a questionnaire recording their sex, age, height, weight, and a history of any previous LBP. No subjects had any previous experience of ADIM exercise. The purpose of the study was explained to the participants and informed consents were obtained. The study protocol was approved by the institutional review board of the Sahmyook University in Seoul.

\section{Measurements}

A RUSI system (Myosone U5; Samsung Medison, Korea) with a 7.5-MHz linear transducer was used to obtain images of the EO, IO, and TrA muscles. RUSI measurements were carried out by one examiner with 5 years of RUSI experience. The transducer was transversely placed on the middle abdominal region between the border of the 11 th costal cartilage and the iliac crest [25]. To standardize the position of the transducer, the anterior fascial insertion of the
A

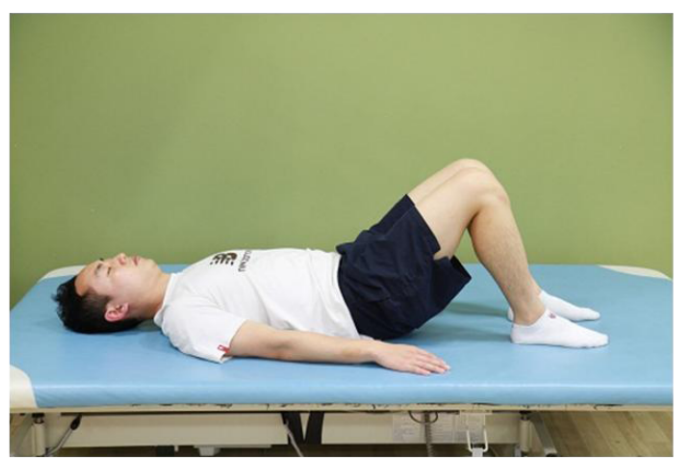

B

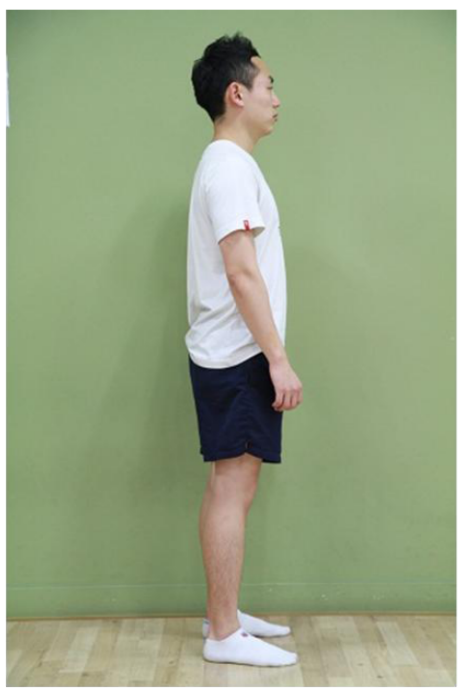

$\mathrm{C}$

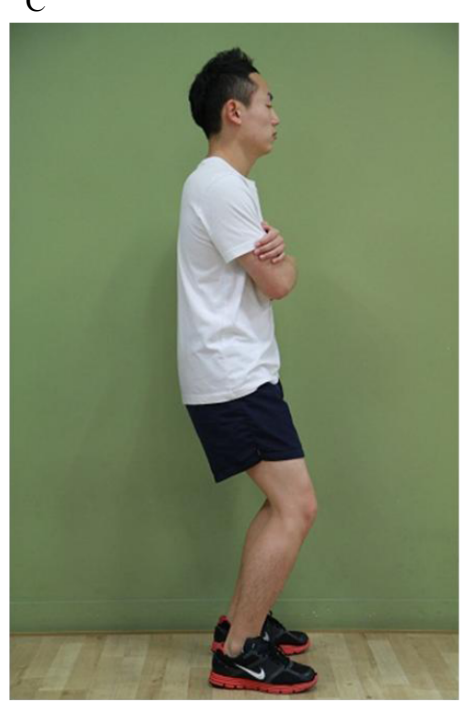

Figure 1. Three examination positions. (A) Crook lying position with hip $60^{\circ}$ flexion, (B) standing position with the feet hip width apart and knees straight, (C) saddle standing position with the knees $20^{\circ}$ flexed. 
TrA was positioned approximately $2 \mathrm{~cm}$ from the medial edge of the ultrasound image [26].

The three positions compared were crook lying, standing, and saddle standing (Figure 1). Two sequential US images were taken at rest and during the ADIM in each of the three positions. Subjects in the crook lying position had their hips flexed to $60^{\circ}$. Subjects in the standing position stood with their feet hip width apart, and subjects in the saddle standing position stood with their feet hip width apart and with knees flexed to $20^{\circ}$. The subjects were verbally cued to draw in their abdominal wall with the intention of pulling their navel towards their low back [27]. The thickness of the TrA, IO, and EO muscles were collected at end of inspiration when the TrA was at its thinnest [28].

The RUSI image showed skin, fat, and three muscles. On the RUSI image, the top skin was mildly echogenic, and the fat under the skin was hypoechoic. The three muscles were the EO, IO, and TrA from superficial to deep, respectively (Figure 2). Each muscle layer was differentiated from the next by the hyperechoic epimysium. The examiners measured the vertical length $2 \mathrm{~cm}$ away from the anterior fascial insertion of the TrA on the RUSI between the inferior echogenic fascial line and the superior line of each muscle.

\section{Data analysis}

Statistical analysis was performed using the IBM SPSS Statistics 19.0 (IBM Co., Armonk, NY, USA). The general characteristics of the participants were analyzed by descriptive statistics and presented as mean (standard deviation)

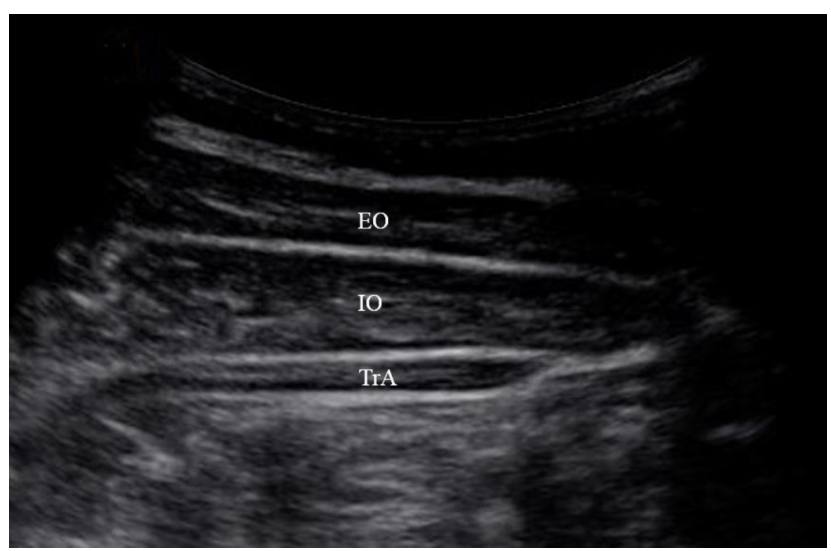

Figure 2. Rehabilitative ultrasound image of the lateral abdominal muscle was measured. The most superficial layer is the external oblique (EO) muscle, the middle layer is the internal oblique (IO) muscle, and deepest layer is the transversus abdominis (TrA) muscle.
(SD). The changes in muscle thickness of the TrA, IO, and $\mathrm{EO}$ at rest and during the ADIM in the crook lying, standing, and saddle standing positions were compared using repeated measure ANOVA. Statistical significance was set at 0.05 .

\section{Results}

Participants had a mean age of 22.3 (2.3) years (mean [SD]), a mean height of $168.7(7.8) \mathrm{cm}$, a mean weight of $62.6(10.2) \mathrm{kg}$, a mean bust circumference of $87.0(7.4) \mathrm{cm}$, a mean waist circumference of $76.2(7.0) \mathrm{cm}$, and a mean body mass index of 21.9 (2.7) (Table 1).

The thicknesses of the TrA, IO, and EO during rest and during ADIM in crook lying, standing, and saddle standing are summarized in Table 2. During ADIM, the TrA thickness was significantly increased in the crook lying, standing, and saddle standing positions greater than during resting. IO thickness was significantly greater in standing and saddle standing than in crook lying $(p<0.05)$. EO thickness was not significantly changed in all the three positions. In the standing and saddle standing position, the TrA and IO thickness were significantly higher than in the crook lying position. However, there was no significant change of the IO or TrA thickness between the standing and saddle standing positions (Table 2). Figure 3 shows the changes in TrA, IO, and EO thickness according to the three positions.

\section{Discussion}

In this cross-sectional study, the TrA thickness was significantly increased in the standing and saddle standing positions. Standing and saddle standing produced statistically significant increases in the IO thickness. One possible

Table 1. General characteristics of subjects

$(\mathrm{N}=28)$

\begin{tabular}{lc}
\hline \multicolumn{1}{c}{ Parameters } & \multicolumn{1}{c}{ Value } \\
\hline Sex & \\
Male/female & $14 / 14(50.0 / 50.0)$ \\
Dominant side & \\
Right/left & $27 / 1(96.41 / 3.6)$ \\
Age $(\mathrm{y})$ & $22.3(2.3)$ \\
Height $(\mathrm{cm})$ & $168.7(7.8)$ \\
Weight $(\mathrm{kg})$ & $62.6(10.2)$ \\
Body mass index & $21.9(2.7)$ \\
Bust circumference $(\mathrm{cm})$ & $87.0(7.4)$ \\
Waist circumference $(\mathrm{cm})$ & $76.2(7.0)$ \\
\hline
\end{tabular}

Values are presented as $\mathrm{n}(\%)$ or mean (SD). 
Table 2. Changes in muscle thickness of TrA, IO, and EO with resting, crook lying, standing, and saddle standing positions during ADIM

\begin{tabular}{ccccc}
\hline & \multicolumn{4}{c}{ Positions } \\
\cline { 2 - 5 } Parameter & Resting & ADIM crook lying & ADIM standing & ADIM saddle standing \\
\hline TrA $(\mathrm{cm})$ & $0.21(0.07)$ & $0.33(0.11)^{\mathrm{a}}$ & $0.42(0.16)^{\mathrm{a}, \mathrm{b}}$ & $0.46(0.20)^{\mathrm{a}, \mathrm{b}}$ \\
IO (cm) & $0.66(0.19)$ & $0.74(0.25)$ & $0.88(0.29)^{\mathrm{a}, \mathrm{b}}$ & $0.88(0.27)^{\mathrm{a}, \mathrm{b}}$ \\
EO (cm) & $0.43(0.13)$ & $0.40(0.14)$ & $0.40(0.12)$ & $0.41(0.14)$ \\
\hline
\end{tabular}

Values are presented as mean (SD).

TrA: transversus abdominis, IO: internal oblique muscle, EO: external oblique muscle, ADIM:abdominal draw-in maneuver.

${ }^{a}$ Significant difference compared to resting $(p<0.05)$. ${ }^{\mathrm{b}}$ Significant difference compared to ADIM in crook lying $(p<0.05)$. ${ }^{\mathrm{c}}$ Significant difference compared to ADIM in standing $(p<0.05)$.

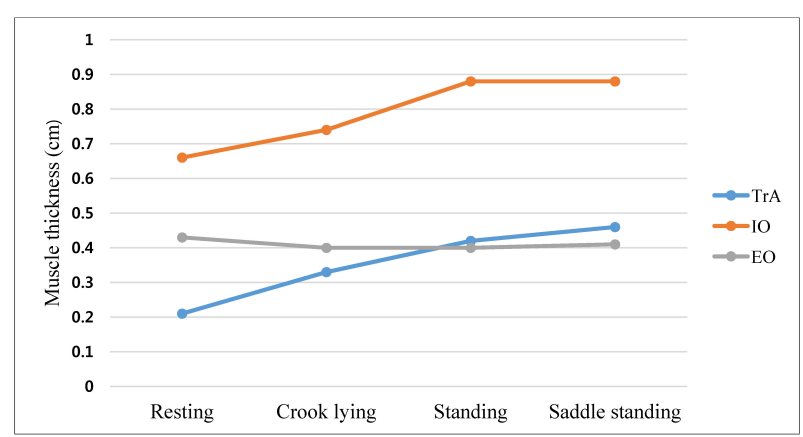

Figure 3. Changes in transversus abdominis (TrA), internal oblique (IO), and external oblique (EO) thickness according to the positions (crook lying, standing, and saddle standing) during resting and abdominal draw-in maneuver.

explanation for these results might be the need for increased activation of the TrA and IO muscles to maintain standing posture with a smaller base of support than in the crook lying posture [29]. Beith et al. [29] demonstrated that differences in thickness were found within the TrA and IO muscles in standing compared with lying. They suggest standing is less stable than lying and requires more support for the vertebral column, and therefore requires more activation of the TrA. The finding of a constant EO thickness suggests the EO plays no part in stabilizing the spine. The change in thickness of the IO muscle was intriguing, but there is some suggestion that there might be different activation patterns in different parts of the IO muscle.

We investigated abdominal muscle thickness in the saddle standing position, which reduces the support from the knee hyperextension when standing. Many studies have used the saddle standing position with knees flexed between $20^{\circ}-30^{\circ}$ to reduce support by the knee skeletal system $[21,30]$. No significant differences were found in the TrA and IO thick- ness between standing and saddle standing positions. However, in the saddle standing position, TrA thickness we observed that the increase more than in the standing position (Figure 3). Previous studies suggest that the standing position should require smaller tonic recruitments of the TrA muscle compared to saddle standing because the body weight loaded onto the spine would be decreased by support from the knee skeletal system [21]. Hwang et al. [21] suggest that saddle standing with the knees flexed to $20^{\circ}$ during an ADIM is the most effective position. In their research, as knee flexion increased, support by the knee skeletal system decreased. In other words, the recruitment of the TrA increases in more difficult positions [31]. Additionally, Richardson et al. demonstrated that as knee flexion increases, the TrA activity also increases to stabilize the sacroiliac joint as well as the lumbar and pelvic regions [32].

Previous studies have indicated that the supine position is more effective at recruitment of the TrA activation than the standing position [30,33]. However, in line with this study, many researchers recommend the standing position for an ADIM [21-23].

LBP is often a result of suboptimal lumbar segmental control and may be partially due to dysfunction in local segmental muscles such as the TrA [34]. The ADIM has been shown to be effective in the treatment of LBP and significantly reduces LBP symptoms and disability [3,23]. Therefore, we suggest a further study targeting LBP patients for the appropriate position of the ADIM.

The present study suggests that standing and saddle standing positions could be recommended for the ADIM to maximize recruitment of the TrA and IO activation. Specifically, the saddle standing position with knees flexed to $20^{\circ}$ was observed to increase the TrA activation more than the standing position. These findings should be considered when core 
stability exercises such as the ADIM are conducted.

\section{Conflict of Interest}

The authors declared no potential conflicts of interest with respect to the authorship and/or publication of this article.

\section{References}

1. Moffett JK, Torgerson D, Bell-Syer S, Jackson D, Llewlyn-Phillips $\mathrm{H}$, Farrin A, et al. Randomised controlled trial of exercise for low back pain: clinical outcomes, costs, and preferences. BMJ 1999;319:279-83.

2. Rainville J, Hartigan C, Jouve C, Martinez E. The influence of intense exercise-based physical therapy program on back pain anticipated before and induced by physical activities. Spine J 2004;4:176-83.

3. Ferreira PH, Ferreira ML, Maher CG, Herbert RD, Refshauge K. Specific stabilisation exercise for spinal and pelvic pain: a systematic review. Aust J Physiother 2006;52:79-88.

4. O'Sullivan PB, Phyty GD, Twomey LT, Allison GT. Evaluation of specific stabilizing exercise in the treatment of chronic low back pain with radiologic diagnosis of spondylolysis or spondylolisthesis. Spine (Phila Pa 1976) 1997;22:2959-67.

5. De Troyer A, Estenne M, Ninane V, Van Gansbeke D, Gorini M. Transversus abdominis muscle function in humans. J Appl Physiol (1985) 1990;68:1010-6.

6. Hodges PW. Is there a role for transversus abdominis in lumbo-pelvic stability? Man Ther 1999;4:74-86.

7. Hodges PW, Richardson CA. Inefficient muscular stabilization of the lumbar spine associated with low back pain. A motor control evaluation of transversus abdominis. Spine (Phila Pa 1976) 1996;21:2640-50.

8. Cresswell AG, Oddsson L, Thorstensson A. The influence of sudden perturbations on trunk muscle activity and intra-abdominal pressure while standing. Exp Brain Res 1994;98:336-41.

9. McGalliard MK, Dedrick GS, Brismée JM, Cook CE, Apte GG, Sizer PS Jr. Changes in transversus abdominis thickness with use of the abdominal drawing-in maneuver during a functional task. PM R 2010;2:187-94; quiz 226.

10. Teyhen DS, Rieger JL, Westrick RB, Miller AC, Molloy JM, Childs JD. Changes in deep abdominal muscle thickness during common trunk-strengthening exercises using ultrasound imaging. J Orthop Sports Phys Ther 2008;38:596-605.

11. Hides JA, Stanton WR, McMahon S, Sims K, Richardson CA. Effect of stabilization training on multifidus muscle cross-sectional area among young elite cricketers with low back pain. J Orthop Sports Phys Ther 2008;38:101-8.

12. Whittaker JL. Ultrasound imaging of the lateral abdominal wall muscles in individuals with lumbopelvic pain and signs of concurrent hypocapnia. Man Ther 2008;13:404-10.

13. Lee JP, Tseng WY, Shau YW, Wang CL, Wang HK, Wang SF. Measurement of segmental cervical multifidus contraction by ultrasonography in asymptomatic adults. Man Ther 2007;12:286-94.

14. Hides JA, Richardson CA, Jull GA. Magnetic resonance imaging and ultrasonography of the lumbar multifidus muscle. Comparison of two different modalities. Spine (Phila Pa 1976) 1995;20:54-8.

15. Mendis MD, Wilson SJ, Stanton W, Hides JA. Validity of real-time ultrasound imaging to measure anterior hip muscle size: a comparison with magnetic resonance imaging. J Orthop Sports Phys Ther 2010;40:577-81.

16. Hides J, Wilson S, Stanton W, McMahon S, Keto H, McMahon $\mathrm{K}$, et al. An MRI investigation into the function of the transversus abdominis muscle during "drawing-in" of the abdominal wall. Spine (Phila Pa 1976) 2006;31:E175-8.

17. Bjerkefors A, Ekblom MM, Josefsson K, Thorstensson A. Deep and superficial abdominal muscle activation during trunk stabilization exercises with and without instruction to hollow. Man Ther 2010;15:502-7.

18. Madokoro S, Miaki H, Yamazaki T. The effect of the abdominal drawing-in manoeuvre during forward steps. J Phys Ther Sci 2014;26:889-93.

19. Urquhart DM, Hodges PW, Allen TJ, Story IH. Abdominal muscle recruitment during a range of voluntary exercises. Man Ther 2005; 10:144-53.

20. Park KN, Cynn HS, Kwon OY, Lee WH, Ha SM, Kim SJ, et al. Effects of the abdominal drawing-in maneuver on muscle activity, pelvic motions, and knee flexion during active prone knee flexion in patients with lumbar extension rotation syndrome. Arch Phys Med Rehabil 2011;92:1477-83.

21. Hwang YI, Kim JJ, Park DJ. The preferential contraction ratios of transversus abdominis on the variations of knee angles during abdominal drawing-in maneuver in wall support standing. J Exerc Rehabil 2014;10:100-5.

22. Mew R. Comparison of changes in abdominal muscle thickness between standing and crook lying during active abdominal hollowing using ultrasound imaging. Man Ther 2009;14:690-5.

23. O'Sullivan PB. Lumbar segmental 'instability': clinical presentation and specific stabilizing exercise management. Man Ther 2000;5:2-12.

24. Akuthota V, Nadler SF. Core strengthening. Arch Phys Med Rehabil 2004;85(3 Suppl 1):S86-92.

25. Teyhen DS, Miltenberger CE, Deiters HM, Del Toro YM, Pulliam JN, Childs JD, et al. The use of ultrasound imaging of the abdominal drawing-in maneuver in subjects with low back pain. J Orthop Sports Phys Ther 2005;35:346-55.

26. Hides JA, Miokovic T, Belavý DL, Stanton WR, Richardson CA. Ultrasound imaging assessment of abdominal muscle function during drawing-in of the abdominal wall: an intrarater reliability study. J Orthop Sports Phys Ther 2007;37:480-6.

27. Richardson CA, Jull GA. Muscle control-pain control. What exercises would you prescribe? Man Ther 1995;1:2-10.

28. Misuri G, Colagrande S, Gorini M, Iandelli I, Mancini M, Duranti R, et al. In vivo ultrasound assessment of respiratory function of abdominal muscles in normal subjects. Eur Respir J 1997;10:2861-7.

29. Beith ID, Critchley DJ, Copeman E, Newham DJ. Changes in thickness of the left and right human abdominal muscles in standing and lying. J Physiol (Camb) 2001;531(Suppl):147P.

30. Lee JC, Lee SK, Kim K. Comparison of abdominal muscle activity in relation to knee angles during abdominal drawing-in exercises using pressure biofeedback. J Phys Ther Sci 2013;25:1255-7.

31. Ainscough-Potts AM, Morrissey MC, Critchley D. The response 
of the transverse abdominis and internal oblique muscles to different postures. Man Ther 2006;11:54-60.

32. Richardson CA, Snijders CJ, Hides JA, Damen L, Pas MS, Storm $\mathrm{J}$. The relation between the transversus abdominis muscles, sacroiliac joint mechanics, and low back pain. Spine (Phila Pa 1976) 2002;27:399-405.

33. Manshadi FD, Parnianpour M, Sarrafzadeh J, Azghani MR,
Kazemnejad A. Abdominal hollowing and lateral abdominal wall muscles' activity in both healthy men \& women: an ultrasonic assessment in supine and standing positions. J Bodyw Mov Ther 2011;15:108-13.

34. Panjabi MM. The stabilizing system of the spine. Part I. Function, dysfunction, adaptation, and enhancement. J Spinal Disord 1992;5:383-9; discussion 397. 